\title{
Application of Two Intervention Programs in Order to Optimize Motivation and to Improve Eating Habits in Adult and Elderly Women
}

\author{
by \\ Marta Leyton ${ }^{1}$, Marco Batista², Susana Lobato ${ }^{3}, M^{\underline{a}}$ Isabel Aspano ${ }^{4}$, Ruth Jiménez ${ }^{5}$
}

The objective of this study was to analyse the effectiveness of two intervention programs: a physical exercise program with strategies to support the three basic psychological needs (autonomy, competence and relatedness); and a physical exercise program with nutritional education in order to improve the lifestyles of adult and elderly women who practiced functional maintenance. The Self-Determination Theory was applied as the theoretical framework. A sample of 135 women aged between 40 and 88 years $(59.66 \pm 10.76)$ who enrolled in a 12-week functional maintenance program and attended 24 exercise classes took part in the study. A quasi-experimental study was performed where strategies to support the three basic psychological needs were applied to one group and strategies for the improvement of eating habits were applied to the other group. No strategy was applied to the control group. The main results showed an improvement in experimental groups I and II when compared to the control group regarding the variables of autonomy, competence, intrinsic regulation, identified regulation, introjected regulation, external regulation and eating habits, after the application of the intervention programs. The conclusion is that both intervention programs were successful with this project's participants and that it is crucial to promote such intervention programs in functional maintenance classes, as they foster healthy lifestyles among participants.

Key words: self-determination theory, nutritional education, physical activity, healthy lifestyle.

\section{Introduction}

If the objective is to promote and educate for health, the population's lifestyles must be taken into consideration. It may be considered that the lifestyle is a behaviour learned throughout life, thus, according to Tuero and Márquez (2009), it may be inferred that a person's lifestyle is composed of his/her normal reactions and of the behaviour standards developed during his/her socialization process. There is a universal consensus which implies that everything related to adequate nutrition, physical activity (PA) practises and personal hygiene boosts or protects health; on the other hand, stress, lack of rest, smoking, sedentary lifestyles and the abuse of alcohol and/or psychoactive substances constitute a risk for health (Casado-Pérez et al., 2015). Furthermore, studies show that PA influences other healthy behaviours, such as balanced eating habits, along with a decrease of those which constitute a risk, such as alcohol consumption and smoking (Giménez et al., 2015). It is a fact that those aspects related to food and nutrition are

\footnotetext{
1 - University Autónoma of Madrid, Spain.

2 - Polytechnic Institute of Castelo Branco, Portugal.

3 - Ruth Jiménez Castuera, Professor, University of Extremadura, Spain.

4 - Primary School CRA Via de la Plata, Cáceres, Spain.

5 - University of Extremadura, Spain.
} 
even more part of public agendas. However, greater consideration of the stakeholders is necessary, mainly in the research and coordination processes in these subjects. Currently, there are many studies about intervention programs with the aim of achieving weight loss in the elderly population. For example, Foster-Schubert et al. (2012) carried out an intervention in 439 postmenopausal sedentary women to determine the effect of a caloriereduced, low-fat diet, a moderate-intensity, facility-based aerobic exercise program, and the combination of both interventions. They concluded that among postmenopausal women lifestyle-change involving diet, exercise, or both combined over 1 year improved body mass and adiposity values, with the greatest change arising from the combined intervention.

The lack of PA is considered to be a serious health problem in today's society, thus giving great importance to motivation towards physical exercise and the promotion of engagement with it in the psychology of exercise. The theoretical framework supporting the study is the Self-Determination Theory (SDT) (Deci and Ryan, 1985). This macro level theory of motivation is based on contextual influences and interpersonal perceptions to explain at which level human being's behaviours are volitional and selfdetermined. It establishes a continuum that involves the different types of self-determination, and creates three fundamental types of motivation: intrinsic motivation (participation for the pleasure of practising the activity), extrinsic motivation (participation as a means to accomplish other goals) and amotivation (lack of reasons to participate). This theory assumes that people are organisms with innate tendencies for psychological development, and it explains how the social environment may encourage or discourage these natural tendencies for psychological growth (Deci and Ryan, 1985). The nutrients which boost personal development, healthy functioning and well-being are what the SDT defines as basic psychological needs, considering them to be something innate, universal and essential which human beings must satisfy (Deci and Ryan, 1985). It establishes three main needs: competence (the wish to effectively interact with the environment in order to feel competent), autonomy (the wish to engage with an activity due to one's own choice) and relatedness (the wish to relate positively with other individuals). Thus, the level and type of motivation of the individual in a determined environment will depend on the satisfaction of these three needs (Deci and Ryan, 1985).

At a later stage, the Hierarchical Model of Intrinsic and Extrinsic Motivation (HMIEM) (Vallerand, 1997) was developed with the aim of improving and relating the constructs of the SDT (Deci and Ryan, 1985), gradually converting it into the main theory when it comes to explaining motivation regarding sports and exercise, and being one of the first theories to consider a complete analysis of the motivational and cognitive processes. The Vallerand's model (2007) is based on four fundamental pillars: causal factors (which will influence the three basic psychological needs); triple construal of motivation (Deci and Ryan, 1985); three hierarchical levels of generality (global, contextual and situational) and motivational consequences (affective, behavioural or cognitive). Thus, if we know the type of motivation an individual has (mediated by the satisfaction of the three basic psychological needs, which were mediated by the contextual background) and if we know how the levels of self-determination are associated with the psychological functioning, we may predict the impact of the different types of motivation in the provoked consequences (Vlachopoulos and Michailidou, 2006). Research indicates the need to develop the participant's self-determined motivation to support the engagement with sports to achieve important benefits for health (MarcosPardo et al., 2014).

Edmunds et al. (2007), using the SDT as a basis to analyse healthy PA charts in a sample composed of overweight and obese participants, showed that the most self-determined forms of motivation positively preceded adaptive consequences, such as engagement with the prescribed sports practice and with well-being.

Fortier et al. (2007) showed, after an intervention program based on SDT, higher autonomy support and autonomous motivation at the 6th week and higher PA levels at the 13th week for the experimental group. These examples demonstrate the versatility and applicability of the SDT model for health behavior change.

Hence, this study integrated the intention 
to be physically active, basic psychological needs and the SDT with the purpose of understanding the psychosocial determinants of practising PA in adults and elderly women. Much previous research had been descriptive or created artificial situations to test theories. This research introduced intervention into a real life situation by identifying a PA program which was already running.

Therefore, we formulated the following hypothesis:

I- The application of the physical exercise intervention program with strategies for supporting the three basic psychological needs (autonomy, competence and relatedness) would improve the most self-determined motivation of the participants.

II- The application of the physical exercise intervention program with nutritional education would improve the eating habits of the participants.

III- The functional maintenance programs would improve the physical condition of the participants.

\section{Methods}

\section{Participants}

A sample of 135 participants was used, composed of women who practiced functional maintenance, aged between 40 and 88 years (59.66 \pm 10.76 ). $56.30 \%$ of the women performed low intensity physical activities, apart from their functional maintenance classes. The participants in this sample group were selected through nonprobabilistic intentional sampling by conglomerate of the different functional maintenance groups provided by the City Council. The sample was divided into several groups:

- Control Group: the participants practised functional maintenance and no intervention program was applied. The Control Group was composed of 50 participants with an average age of $57.40( \pm 8.60)$ years, selected from three different functional maintenance groups.

Experimental Group I: the participants practised functional maintenance and the two intervention programs were applied. Experimental Group I was composed of 40 participants with an average age of $60.35( \pm 13.80)$ years, selected from three different functional maintenance groups.

- $\quad$ Experimental Group II: the participants practised functional maintenance and the two intervention programs were applied. Experimental Group II was composed of 45 participants with an average age of $61.09( \pm 10.71)$ years, selected from three different functional maintenance groups.

Measures

The instruments used to measure the variables which determined the effects of these programs were:

To measure the Motivation Level, the Behavioural Regulation in Exercise Questionnaire-2 (BREQ-2) was used. It was translated into Spanish by Moreno et al. (2007a), from the Behavioral Regulation in Exercise Questionnaire-2 (BREQ-2; Markland and Tobin, 2004). It is composed of 19 items which measure the stages on the continuum of self-determination in physical exercise participants: intrinsic regulation, identified regulation, introjected regulation, external regulation and amotivation. The Cronbach's alpha (a) went from .60 to .82 during the three measurements.

In order to assess the Basic Psychological Needs (autonomy, competence and relatedness) the Spanish version (Sánchez and Núñez, 2007) of the Basic Psychological Needs Evaluation Scale (BPNES) of Vlachopoulos and Michailidou (2006) was used. It is composed of a total of 12 items which measure the satisfaction of the three basic psychological needs of autonomy, competence and relatedness. The Cronbach's alpha (a) ranged from .64 to .80 during the three measurements.

Intention to be physically active was measured through the questionnaire of Hein et al. (2004) i.e., the Intention to be Physically Active Scale, with the adapted version, translated into Spanish by Moreno et al. (2007b). It is composed of a single factor of 5 items. The Cronbach's alpha (a) was .70 in the three measurements.

- $\quad$ Regarding eating habits, the Healthy Lifestyles Questionnaire by Wold (1995) was used, translated and validated into Spanish by Jiménez et al. (2007). Only the 10 items related to food were selected, which were grouped in the eating habits factor. The Cronbach's alpha (a) were .60 .61 and .70 in the three measurements, respectively.

Some factors showed reliability below the 
recommended .70, however, given the small number of items composing the factors (three or four for each factor), the observed internal consistency may be marginally accepted (Nunnally and Bernstein, 1994).

Every item in the questionnaires was responded to through a Likert type scale with a range from 0 (totally disagree) to 5 (totally agree).

Physical condition was measured through the ECFA tests (Fitness Assessment in the Elderly), consisting of tests evaluating the following variables: body mass index, hand grip strength, single foot balance, abdominal strength, aerobic stamina, trunk flexibility and fitness index. These tests were used, as we considered them easy to apply and that they enabled the collection of measurements of the major physical capabilities during the sessions.

\section{Procedures}

Once the research had been approved by the Committee for Ethics, we contacted the City Council to determine the number of functional maintenance groups available in the city. When the groups were formed, it was randomly determined who would be part of the Control Group, of the Experimental Group I and the Experimental Group II. At a later stage, we contacted the instructors of the different groups to explain all details related to the study. We also contacted the participants, to whom we gave an informed consent form in which the study and each of the tests were described in detail.

It is important to mention that before the beginning of the intervention programs, following the first measurement of all the variables, we found no significant differences among the different marked groups (Control, Experimental I and Experimental II), which enabled the application of the intervention programs.

A quasi-experimental study was carried out, with a $2 \times 2$ factor design with a counterbalance of the treatments and a control group. Thus, the participants were compared at different times to determine the impact of the independent variable on the dependent variables (Figure 1). The application time of the programs was three months. Both the Control Group and the Experimental Groups had functional maintenance classes.

The functional maintenance classes and the intervention programs were applied by the same person. The functional maintenance classes consisted of physical activities focused on improving strength, flexibility and stamina. To achieve this, individual and/or group activities were performed to music using additional material (balls, weights, fit balls, among others). As this was a group of adult and elderly women, exercises with heavy resistance were avoided.

The Control Group had only one traditional functional maintenance class during the three months intervention. For Experimental Group I, during the first 12 sessions of the functional maintenance classes, a physical exercise program with strategies for supporting the three basic psychological needs (autonomy, competence and relatedness) was applied; during the following 12 sessions, a physical exercise program with nutritional education was conducted.

For Experimental Group II, during the first 12 sessions of the functional maintenance classes, a physical exercise program with nutritional education was applied; during the following 12 sessions, strategies for supporting the three basic psychological needs (autonomy, competence and relatedness) were implemented.

All the functional maintenance classes were divided into a warm-up (to activate the muscles to be exercised), the main phase (execution of aerobics, strength and flexibility exercises) and a cool down (execution of stretches and relaxation exercises and five minutes of reflection on the contents exercised).

The intervention programs and the strategies to carry them out were developed by a group of experts which included: a nutritionist, a psychologist and a PhD in Sport Sciences.

In the physical exercise program which included strategies for supporting the three basic psychological needs (autonomy, competence and relatedness), strategies of Moreno and Martínez (2006) were included. These strategies need to be considered in any PA in order to promote such needs, and they were used in planning the activities carried out in the intervention program. Strategies such as establishing realistic goals, using positive feedback, social environment related to the task and supporting relatedness were included among others, all of which were aimed at the improvement of such basic psychological needs. 
According to these authors, in order to develop the self-need of autonomy, the establishment of realistic goals may promote the extension of training in time, as well as the consolidation of the intention to be physically active. Thus, the participants were included in the definition of the goals in order to increase their autonomy. They were given the option between several exercises to work on a specific group of muscles, from which they were to choose one. The goals of the proposed activities were described in such a way that the positive perception towards the activity and the sense of autonomy were increased. Within the context of non-competitive physical activity, it is useful to explain what is going to be done and with what objectives. When planning a strength training session, it is not enough to focus only on exercise execution, it is also necessary to explain to that person which muscle groups are involved, the benefits of muscular improvement and the precautions to have in mind (Moreno and Martínez, 2006). Rewards were used in moderation because, if used inappropriately, they may decrease motivation and autonomy.

To stimulate the self-need of competition, positive retro-feeding was facilitated by stimulating the participants, with encouragements such as: "Good work! You are doing great!", "I really like how you did it!", "Your posture for the leg exercise is really good!". We also avoided expressions such as: "You are positioning your legs wrong". A motivational environment was created for the task. The participants focused on improving their own performance, thus avoiding external pressure which would create unnecessary stress to them. The participant was guided by using expressions such as: "Forget how the others are doing it, focus on improving your own performance.", and avoiding expressions such as: "You have to do it perfectly, no matter what it takes.", with the goal of improving the self-competence sense. This way, Ntoumanis (2001), evidenced the independent and interactive effects of the goal guidance and the perceived competence in seven motivational variables with the different levels of self-determination. The results suggest that the role of guidance towards the task promotes self-determined motivation in sports. Expressions such as: "I don't know how to do this" or "I can't do it", were avoided and guidance such as: "This is why we are here - to learn!", "If you keep practicing, you will see that it is not that hard" was provided. This is why it was paramount to plan the activities per levels of difficulty and to provide options within an activity.

To stimulate the basic psychological need of social relationships, the strategies were: to use empathy (for example: to follow the rhythm of a fellow participant), to promote bonding (in games or situations where there are several participants and that involve handling an object which must go through every member of the group), to promote the sense of care towards others (to show interest in the condition of the activity partner), to promote a sense of relationship among the participants (the importance of conducting activities of interaction with others in a large group, for example, presentation games or ice breakers), as well as to promote group cohesion, to maintain a good relationship with the coach, to engage in brainstorming and to solve problems together.

In the physical exercise with the nutritional education program, based on the recommendations of the Work group "Salud Pública" (Public Health) of the Spanish Nutritional Association (SEN) (Arbonés et al., 2003) and with the contribution of an expert in nutrition, physical activities were performed, with integration of nutritional education where the main contents included were the major components of food, vitamins, healthy food and recommended diets according to the season of the year.

The strategies used to improve eating habits were based on the application of physical activities and games, both with a nutritional component. One of the examples of the activities used was using printed material related to healthy and non-healthy food during the sessions, instead of using colors or animals, information related to healthy food was used to execute games or physical activities. Reflecting at the end of the session was very important in this program, as it helped in absorbing concepts and to clear doubts about diets, healthy food and eating habits.

It is important to point out that 3 measurements were performed on all the groups: before the start of the study, after the first 12 sessions and at the end of the study, i.e., after 
completion of the 24 sessions.

\section{Statistical Analysis}

After performing a Kolmogorov-Smirnov normality test and a Levene variance unity test, the results showed a normal distribution of the data in both tests. A confirmatory factorial analysis was performed to determine the validity of the different instruments; at a later stage, reliability analyses were performed and the different variables were created.

Firstly, it was determined that there were no significant differences in most of the variables in the pre-test measurement among the selected groups. There were only significant differences in the heart rate after $2 \mathrm{~km}$ and time after $2 \mathrm{~km}$, which allowed the research to continue without that contaminant variable.

The repeated measurements variance analysis is presented below. MANOVA was applied in the group factors (Control Group, Experimental Group I and Experimental Group II) along with 3 measurements (pre-test, intermediate, post-test), followed by the Bonferroni post hoc to identify the possible intra- and inter-group differences. The statistical power of the data was also calculated.

SPSS19.0. (Predictive Analytic Software) software was used for the treatment and analysis of the data. The $p<.05$ and $p<.01$ values were used for the statistical significance.

\section{Results}

The intra- and inter-group differences of all the variables in each of the three performed measurements (pre-test, intermediate, post-test) are shown below. With regard to the inter- and intra-group repeated measurements variance analysis (Tables 1 and 2), a significant difference in most of the measured variables could be observed, with no differences found between the Control Group and the Experimental Groups in the body mass, body mass index, right leg and left leg balance, abdominal strength, right hand and left hand grip strength, leg and trunk flexibility, amotivation, intention of being physically active, relatedness and in the action and maintenance stages variables.

\begin{tabular}{|c|c|c|}
\hline \multicolumn{3}{|c|}{$\begin{array}{l}\text { Initial Measurement } \\
\text { Application of Physical Tests and Questionnaires }\end{array}$} \\
\hline $\begin{array}{l}\text { Experimental Group II } \\
\text { Intrinsic Motivation Program } \\
\text { application. } \\
\text { ( } 2 \text { sessions per week of } 60 \mathrm{~min} \\
\text { each session, with a total of } 12 \\
\text { sessions). }\end{array}$ & $\begin{array}{l}\text { Experimental Group I } \\
\text { Nutritional Habits Program } \\
\text { application. } \\
\text { ( } 2 \text { sessions per week of } \\
\quad 60 \text { min each session, } \\
\text { with a total of } 12 \text { sessions). }\end{array}$ & $\begin{array}{l}\text { Control Group } \\
\text { No program applied. } \\
\text { Only functional maintenance } \\
\text { ( } 2 \text { sessions per week of } \\
\qquad 60 \text { min each session, } \\
\text { with a total of } 12 \text { sessions). }\end{array}$ \\
\hline \multicolumn{3}{|c|}{$\begin{array}{l}\text { Intermediate Measurement } \\
\text { Application of Physical Tests and Questionnaires }\end{array}$} \\
\hline $\begin{array}{l}\text { Experimental Group I } \\
\text { Nutritional Habits Program } \\
\text { application. } \\
\text { ( } 2 \text { sessions per week of } \\
\quad 60 \text { min each session, } \\
\text { with a total of } 12 \text { sessions). }\end{array}$ & $\begin{array}{l}\text { Experimental Group II } \\
\text { Intrinsic Motivation Program } \\
\text { application. } \\
\text { ( } 2 \text { sessions per week of } 60 \mathrm{~min} \\
\text { each session, with a total of } 12 \\
\text { sessions). }\end{array}$ & $\begin{array}{l}\text { Control Group } \\
\text { No program applied. } \\
\text { Only functional maintenance } \\
\text { ( } 2 \text { sessions per week of } \\
\qquad 60 \text { min each session, } \\
\text { with a total of } 12 \text { sessions). }\end{array}$ \\
\hline \multicolumn{3}{|c|}{$\begin{array}{l}\text { Final Measurement } \\
\text { Application of Physical Tests and Questionnaires }\end{array}$} \\
\hline
\end{tabular}

Figure 1. 
Table 1

Inter and Intra-group differences in regard to the fitness dependent variables.

\begin{tabular}{|c|c|c|c|c|c|c|c|c|c|}
\hline & & GC & & GE1 & & GE2 & & $\begin{array}{l}\text { Inter-group } \\
\text { Contrast }\end{array}$ & \\
\hline $\begin{array}{l}\text { Variable } \\
\text { FITNESS }\end{array}$ & & $M \pm D T$ & Sig. ${ }^{4}$ & $M \pm D T$ & Sig. ${ }^{4}$ & $M \pm D T$ & Sig. ${ }^{4}$ & $F$ & $\eta^{2}$ \\
\hline \multirow{3}{*}{$\begin{array}{l}\text { Body Mass } \\
\text { Index }\end{array}$} & $\mathrm{M} 1^{1}$ & $27.18 \pm 3.96$ & \multirow{3}{*}{.00} & $28.30 \pm 3.95$ & \multirow{3}{*}{.00} & $28.39 \pm 4.83$ & \multirow{3}{*}{.00} & \multirow{3}{*}{11.15} & \multirow{3}{*}{.18} \\
\hline & $\mathrm{M}^{2}{ }^{2}$ & $27.18 \pm 3.97$ & & $27.84 \pm 3.84$ & & $28.18 \pm 4.54$ & & & \\
\hline & $\mathrm{M}^{3}$ & $27.06 \pm 3.94$ & & $27.66 \pm 3.84$ & & $27.79 \pm 4.36$ & & & \\
\hline \multirow{3}{*}{$\begin{array}{l}\text { Right } \\
\text { Balance }\end{array}$} & $\mathrm{M}^{1}{ }^{1}$ & $1.40 \pm 2.18$ & \multirow{3}{*}{.00} & $4.56 \pm 5.76$ & \multirow{3}{*}{.56} & $3.58 \pm 5.39$ & \multirow{3}{*}{.16} & \multirow{3}{*}{2.34} & \multirow{3}{*}{.04} \\
\hline & $\mathrm{M}^{2}$ & $1.30 \pm 2.48$ & & $4.70 \pm 6.16$ & & $3.60 \pm 5.47$ & & & \\
\hline & $\mathrm{M}^{3}$ & $.91 \pm 1.92$ & & $4.15 \pm 6.24$ & & $2.82 \pm 5.10$ & & & \\
\hline \multirow{3}{*}{$\begin{array}{l}\text { Left } \\
\text { Balance }\end{array}$} & $\mathrm{M}^{1}$ & $1.68 \pm 3.02$ & \multirow{3}{*}{.01} & $5.19 \pm 6.18$ & \multirow{3}{*}{.18} & $4.46 \pm 5.92$ & \multirow{3}{*}{.00} & \multirow{3}{*}{2.98} & \multirow{3}{*}{.05} \\
\hline & $\mathrm{M}^{2}{ }^{2}$ & $1.30 \pm 2.67$ & & $4.67 \pm 6.39$ & & $3.42 \pm 5.51$ & & & \\
\hline & $\mathrm{M}^{3}$ & $1.13 \pm 2.75$ & & $4.43 \pm 6.50$ & & $2.66 \pm 5.17$ & & & \\
\hline \multirow{3}{*}{$\begin{array}{l}\text { Abdomina } \\
1 \text { Strength }\end{array}$} & $\mathrm{M}^{1}$ & $.76 \pm .48$ & \multirow{3}{*}{.00} & $.56 \pm .36$ & \multirow{3}{*}{.00} & $.65 \pm .40$ & \multirow{3}{*}{.00} & & \\
\hline & $\mathrm{M}^{2}$ & $.71 \pm .43$ & & $.76 \pm .43$ & & $.85 \pm .42$ & & 8.66 & .16 \\
\hline & $\mathrm{M}^{3}$ & $.87 \pm .42$ & & $.89 \pm .48$ & & $1.04 \pm .40$ & & & \\
\hline Right & $\mathrm{M}^{1}$ & $20.68 \pm 4.95$ & & $20.61 \pm 5.13$ & & $19.17 \pm 5.89$ & & & \\
\hline Hand Grip & $\mathrm{M}^{2}{ }^{2}$ & $21.05 \pm 5.13$ & .00 & $22.49 \pm 5.33$ & .00 & $20.81 \pm 5.60$ & .00 & 14.10 & .17 \\
\hline Strength & $\mathrm{M}^{3}$ & $21.47 \pm 4.98$ & & $23.05 \pm 5.37$ & & $21.92 \pm 5.56$ & & & \\
\hline Left Hand & M1 ${ }^{1}$ & $19.13 \pm 4.43$ & & $20.45 \pm 4.86$ & & $19.15 \pm 5.58$ & & & \\
\hline Grip & $\mathrm{M}^{2}$ & $19.80 \pm 4.38$ & 00 & $21.66 \pm 5.09$ & .00 & $20.66 \pm 5.66$ & .00 & 6.14 & .10 \\
\hline Strength & $\mathrm{M}^{3}$ & $20.15 \pm 4.25$ & .00 & $22.21 \pm 5.14$ & & $21.61 \pm 5.65$ & & & \\
\hline & $\mathrm{M}^{1}$ & $17.50 \pm 6.77$ & & $18.74 \pm 8.77$ & & $16.68 \pm 7.65$ & & & \\
\hline $\begin{array}{l}\text { Irunk } \\
\text { Flexibility }\end{array}$ & $\mathrm{M}^{2}$ & $19.21 \pm 6.98$ & .00 & $18.98 \pm 9.66$ & .07 & $18.84 \pm 7.62$ & .00 & 1.60 & .03 \\
\hline & $\mathrm{M}^{3}$ & $20.33 \pm 7.03$ & & $20.20 \pm 9.51$ & & $20.75 \pm 7.99$ & & & \\
\hline & $\mathrm{M}^{1}$ & $20.48 \pm 6.58$ & & $21.56 \pm 9.16$ & & $19.71 \pm 8.72$ & & & \\
\hline Kight Leg & $\mathrm{M}^{2}{ }^{2}$ & $22.21 \pm 6.85$ & 00 & $21.48 \pm 10.07$ & .17 & $21.62 \pm 8.04$ & .00 & 1.80 & .03 \\
\hline & $\mathrm{M}^{3}$ & $23.23 \pm 6.84$ & & $22.73 \pm 10.11$ & & $23.75 \pm 7.99$ & & & \\
\hline & $\mathrm{M}^{1}{ }^{1}$ & $21.25 \pm 6.83$ & & $21.88 \pm 9.53$ & & $19.85 \pm 8.72$ & & & \\
\hline $\begin{array}{l}\text { Left Leg } \\
\text { Flexibility }\end{array}$ & $\mathrm{M}^{2}$ & $22.79 \pm 7.34$ & .00 & $21.60 \pm 11.05$ & .15 & $21.87 \pm 8.37$ & .00 & 4.01 & .07 \\
\hline & $\mathrm{M}^{3}$ & $23.77 \pm 7.16$ & & $23.08 \pm 10.70$ & & $24.18 \pm 8.58$ & & & \\
\hline & $\mathrm{M}^{1}$ & $20.33 \pm 3.71$ & & $19.71 \pm 3.08$ & & $22.76 \pm 6.38$ & & & \\
\hline Heart Rate & $\mathrm{M}^{2}$ & $20.9 \pm 3.35$ & .10 & $18.08 \pm 2.92$ & .00 & $20.91 \pm 4.65$ & .05 & $\begin{array}{l}14.24^{*} \\
*\end{array}$ & .20 \\
\hline & $\mathrm{M}^{3}$ & $20.14 \pm 3.43$ & .10 & $20.14 \pm 3.43$ & & $19.45 \pm 4.43$ & & & \\
\hline & $\mathrm{M}^{1}{ }^{1}$ & $122.12 \pm 24.52$ & & $101.37 \pm 15.62$ & & $124.95 \pm 31.24$ & & & \\
\hline $\begin{array}{l}\text { Heart Kate } \\
\text { After } 2 \mathrm{~km}\end{array}$ & $\mathrm{M}^{2}$ & $118.12 \pm 23.02$ & .00 & $95.2 \pm 15.07$ & .00 & $128.36 \pm 29.56$ & .00 & $1.5^{*}$ & .03 \\
\hline & M3 $^{3}$ & $116.16 \pm 20.73$ & & $86.77 \pm 11.86$ & & $117.55 \pm 28.01$ & & & \\
\hline & $\mathrm{M}^{1}{ }^{1}$ & $24.14 \pm 4.36$ & & $26.51 \pm 4.03$ & & $21.25 \pm 2.01$ & & & \\
\hline $2 \mathrm{~km}$ & $\mathrm{M}^{2}$ & $24.35 \pm 4.24$ & .00 & $25.57 \pm 4.11$ & .00 & $20.24 \pm 1.73$ & .00 & $\begin{array}{l}30.82^{*} \\
*\end{array}$ & .35 \\
\hline & $\mathrm{M}^{3}$ & $23.97 \pm 4.24$ & .00 & $25.00 \pm 4.14$ & & $19.94 \pm 1.61$ & & & \\
\hline & $\mathrm{M}^{1}{ }^{1}$ & $12.49 \pm 12.56$ & & $6.54 \pm 13.65$ & & $19.43 \pm 5.61$ & & & \\
\hline $\mathrm{VO}_{2} \max$ & $\mathrm{M}^{2}$ & $12.24 \pm 12.09$ & .00 & $10.20 \pm 13.81$ & .00 & $22.21 \pm 4.28$ & .00 & $\begin{array}{l}20.64^{*} \\
*\end{array}$ & .26 \\
\hline & M33 $^{3}$ & $13.57 \pm 12.27$ & & $12.91 \pm 13.77$ & & $24.44 \pm 3.93$ & & & \\
\hline & $\mathrm{M}^{1}{ }^{1}$ & $52.52 \pm 36.33$ & & $39.31 \pm 35.55$ & & $76.70 \pm 19.80$ & & & \\
\hline Fitness & $\mathrm{M}^{2}$ & $51.83 \pm 35.46$ & .00 & $49.54 \pm 35.52$ & .00 & $84.23 \pm 13.51$ & .00 & $\begin{array}{l}20.29^{*} \\
*\end{array}$ & .26 \\
\hline & $\mathrm{M}^{3}{ }^{3}$ & $55.64 \pm 35.91$ & & $57.32 \pm 35.21$ & & $90.67 \pm 12.35$ & & & \\
\hline
\end{tabular}




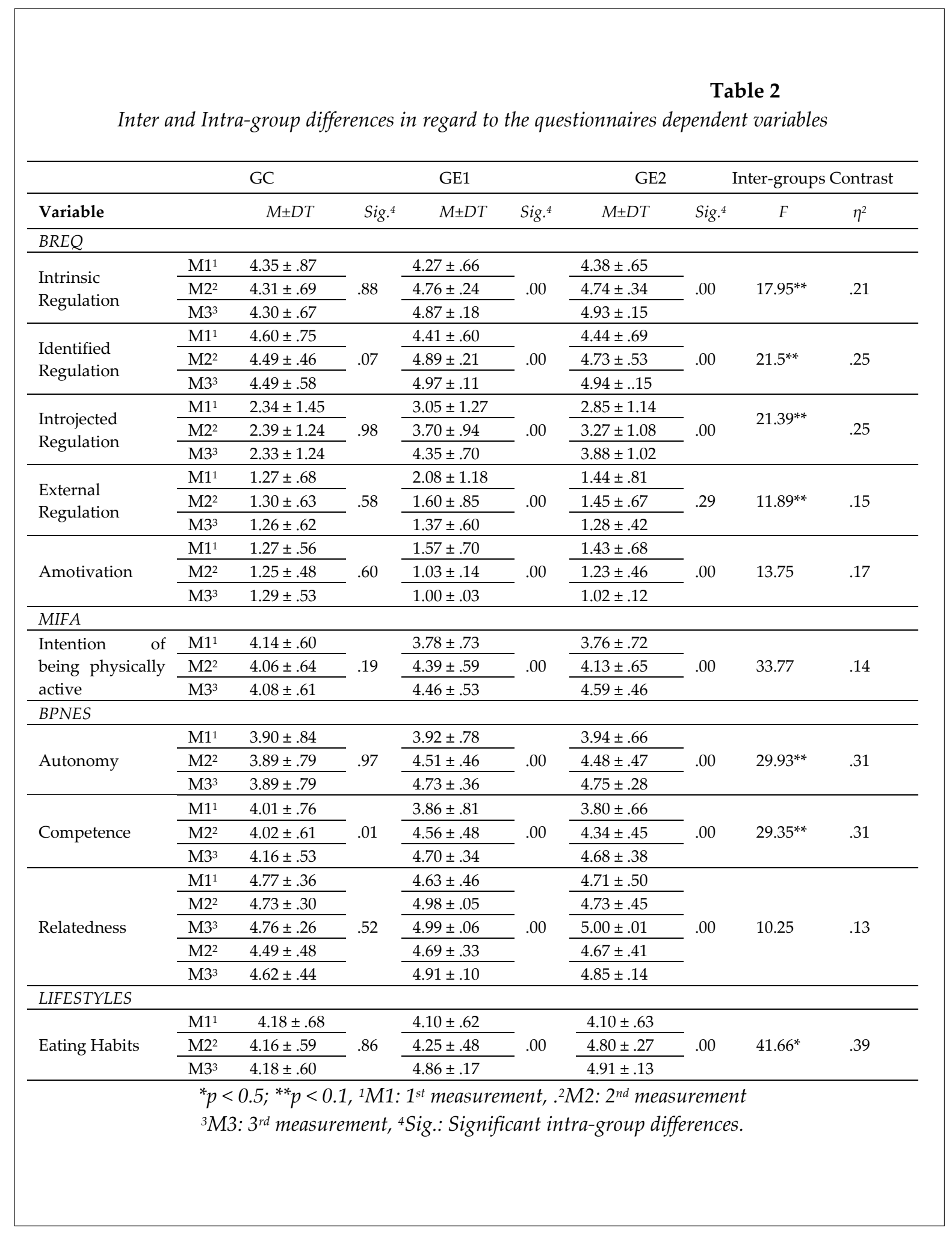

Effect sizes can be evaluated as trivial (00.19), small (0.20-0.49), medium (0.50-0.79) and large (0.80 and greater) (Cohen, 1992).

In the inter-group analysis, significant differences between the groups were observed in the resting heart rate, heart rate after $2 \mathrm{~km}$, time after $2 \mathrm{~km}$, oxygen uptake and fitness index variables, and the magnitude of the effect was acceptable $(\eta 2>.20)$ in all cases except in the heart rate after $2 \mathrm{~km}$ variable $(\eta 2<.20)$. In regard to the intra-group analysis, significant improvements were observed in the three groups in most of the 
fitness variables during and after the application of the intervention programs.

In the inter-group analysis, significant differences were observed between the groups in the intrinsic motivation, identified regulation, external regulation, autonomy, competence and feeding variables, and the magnitude of the effect was acceptable $(\eta 2>.20)$ in all cases except the external regulation variable $(\eta 2<.20)$. In regard to the intra-group analysis, significant improvements were observed in the Experimental Groups in most of the psychological variables during, and after the application of the intervention programs; however, in the Control Group, there were only significant improvements in the identified regulation, competence, action and maintenance stage variables without improvements in the rest of the variables during, and after the application of the intervention programs.

\section{Discussion}

This research intended to show the effects of a theoretical and practical program aiming towards improvement in the basic psychological needs of autonomy, competence and relatedness, along with the most self-determined form of motivation and eating habits, applied in functional maintenance activity in adults and elderly women.

In Hypothesis №. I we stated that the application of the physical exercise intervention program with strategies for supporting the three basic psychological needs (autonomy, competence and relatedness) would improve the most selfdetermined motivation of the participants. The hypothesis was confirmed, as this program improved the satisfaction of the basic psychological needs of autonomy, competence and relatedness. However, with regard to relatedness, no significant differences were obtained, possibly due to the fact that the interventions were executed when the women already had relatedness established between them. Significant differences were found between the Experimental Groups and the Control Group in introjected regulation and external regulation, with both decreasing over the months in the experimental groups. In other research, external regulation was shown to relate with different negative consequences, such as ill-being, stress and drop out of sport (Mouratidis et al., 2010). Thus, the ideal is that PA is not practised due to external pressure, but because there is a real interest in and enjoyment of practising, favouring the satisfaction of the basic psychological needs of autonomy, competence and relatedness and consequently, the most self-determined forms of motivation associated with positive consequences for practising of PA (Vallerand, 2015). Furthermore, an increase of the intrinsic regulation was observed in both experimental groups. Thus the activities which are intrinsically enjoyed, where participants feel competent and autonomous, will succeed in changing the behaviour towards a healthy lifestyle.

This improvement in the most selfdetermined motivation results from the significant increase in the basic psychological needs of autonomy and competence in the experimental groups' participants, with no significant differences found in relation to relatedness. Nevertheless, the average of the first and last measurements did increase in both experimental groups although the same did not occur in the Control Group. It is of paramount importance to support the satisfaction of these basic psychological needs in the physical exercise programs, especially of autonomy (Moustaka et al., 2012; Puigarnau et al., 2016), considering the establishment of objectives and the achievement of individual goals as the most important guidelines.

Therefore, these results are consistent with the HMIEM (Vallerand, 2007), as the satisfaction of the basic psychological needs will produce an increase in the most self-determined motivation, which will favour engagement with the practice of PA (Marcos-Pardo et al., 2014) along with improving the lifestyle (Duda et al., 2014).

Hypothesis №. II stated that the application of the physical exercise intervention program with nutritional education would improve eating habits among the participants. The results confirmed this hypothesis, as significant differences between the Control Group and the Experimental Groups were obtained, with more significance after the application of the program. According to Arbonés et al. (2003), interventions to improve healthy lifestyles first need to focus on and strengthen the improvement 
of intrinsic motivation to improve eating habits in order to facilitate the necessary changes towards healthy behaviours. The success of diet strategies for the promotion of health is normally measured in terms of the adoption of a healthy diet, however, in order for this to happen, it is necessary to offer previous nutritional education. This is very important in the adult population, and especially in the elderly, as there are often rooted eating habits which are very difficult to change. Thus, it is very important to apply programs of physical exercise with nutritional education such as the one we carried out, which had a good effect on the participants. It is logical to consider that the program will improve eating habits as it favours the acquisition of behaviours regarding eating schedules and maintaining a balanced diet. Furthermore, exercising is associated with other beneficial habits for health, such as eating habits, resting, low consumption of alcohol and smoking (Cervelló et al., 2014).

Following Hypothesis №. III, the functional maintenance programs would improve fitness of the participants. It may be concluded that improvements were produced in fitness of all participants, both from the Control Group and the Experimental Groups, as all participated in a functional maintenance program. It is evident that any well structured physical exercise program provides psychological and physiological benefits. If the basic psychological needs continue to be satisfied, more self-determined motivation towards practising PA will be obtained, the person will enjoy it more and there will also be an improvement in the perception of fitness due to the satisfaction of the basic psychological needs (Marcos-Pardo et al., 2015).

The results from this study provide an example of benefits a well structured program aimed towards improvement in a person's lifestyle may have. Based on these indications, it seems advisable to design and develop specific health promotion strategies which promote changes to improve health through eating habits and physical exercise. These strategies may be orientated to support activities such as "Women Day", to promote the use of bicycles and the use of record sheets to track motivation in order to increase commitment to healthy habits. The results found in this study show the importance of the application of programs planned for both the increase of intrinsic motivation and improvement of eating habits. These programs are useful for training professionals in charge of both functional maintenance classes and any group PA, as both programs are applicable to any activity as well as to the male population.

The main limitations of this study include the number of implemented sessions. In order to determine a continued engagement with PA, it would be interesting to apply a later measurement to determine if the found improvements are maintained over time. Secondly, the psychosocial environment was not taken into consideration. This includes the support of significant others (father, mother, brothers/sisters, best friends and workmates), which is important in understanding people's lifestyles (Codina and Pestana, 2012). Finally, there was no systematic recording of the program strategies by the teacher. This leads to some objectivity issues which should be investigated in future studies.

In conclusion, the application of these programs which used strategies for supporting the satisfaction of the basic psychological needs of autonomy, competence and relatedness and for supporting healthy eating habits in adults and elderly women enabled improvements in the participants' lifestyle and created healthy habits which over time may contribute to improvements in their quality of life.

\section{References}

Arbonés G, Carbajal A, Gonzalvo B, González-Gross M, Joyanes M, Marques-Lopes I, Martín Mª, Martínez A, Montero P, Núñez C, Puigdueta I, Quer J, Rivero M, Roset Mª̣A, Sánchez-Muniz FJ, Vaquero Mª̣. Nutrition and dietary recommendations for the elderly "Public Health" working group of the Spanish society. Nutr Hosp, 2003; 18(3): 109-137

Bonito J. Education for health today: some brief notes. Aten Primaria, 2015; 47(1): 32-37 
Casado-Pérez C, Hernández-Barrera V, Jiménez-García R, Fernández-de-Las-Peñas C, Carrasco-Garrido P, Palacios-Ceña D. Physical activity in adult working population: Results from the European National Health Survey for Spain (2009). Aten Primaria, 2015; 47(9): 563-572

Cervelló E, Peruyero F, Montero C, González-Cutre D, Beltrán-Carrillo VJ, Moreno-Murcia JA. Exercise, psychological well-being, sleep quality and situational motivation in physical education students. Cuadernos Psic Dep, 2014; 14(3): 31-38

Codina N, Pestana JV. Study of the relationships between the psychosocial enviroment and women's sport practice. Rev Psica Deporte, 2012; 21(2): 243-251

Cohen J. Methods in psychology. A power primer. Psychol Bull, 1992; 112(1): 155-159

Deci EL, Ryan RM. Intrinsic motivation and Self-Determination in human behaviour. New York: Plenu; 1985

Duda JL, Williams GC, Ntoumanis N, Daley A, Eves FF, Mutrie N, Rouse P, Lodhia R, Blamey R, Jolly K. Effects of a standard provision versus an autonomy supportive exercise referral programme on physical activity, quality of life and well-being indicators: a cluster randomised controlled trial. Int J Behav Nutr Phys Act, 2014; 11(10): 1-15

Edmunds J, Ntoumanis N, Duda JL. Adherence and well-being in overweight and obese patients referred to an exercise on prescription cheme: A Self-Determination Theory perspective. Psychol Sport Exerc, 2007; 8(5): $722-740$

Fortier MS, Sweet SN, O'Sullivan TL, Williams GC. A self-determination process model of physical activity adoption in the context of a randomized controlled trial. Psychol Sport Exerc, 2007; 8(5): 741-757

Foster-Schubert KE, Alfano CM, Duggan CR, Xiao L, Campbell KL, Kong A, Bain CE, Wang CH, Blackburn G, McTiernan A. Effect of diet and exercise, alone or combined, on weight and body composition in overweight-to-obese postmenopausal women. Obesity, 2012; 20(8): 1628-1638

Giménez MRL, López MPM, Urda AIM, Collazos JFR. Eating habits, health and gender in the elderly. Eur J investig health, psycho educa, 2015; 4(1): 31-40

Hein V, Müür M, Koka A. Intention to be physically active after school graduation and its relationship to three types of intrinsic motivation. Eur Phys Educ Rev, 2004; 10(1): 5-19

Jiménez R, Cervelló E, García T, Santos FJ, Iglesias D. Study of the relationship between motivation, extracurricular sports and eating habits and rest in physical education students. Int J Clin Health Psy, 2007; 7(2): 385-401

Marcos-Pardo PJ, Orquín-Castrillón FJ, Belando-Pedreño N, Moreno-Murcia JA. Self-Determination motivation in elderly practitioners of physical exercise. Cuadernos Psic Dep, 2014; 14(3): 149-156

Markland D, Tobin V. A modification of the Behavioral Regulation in Exercise Questionnaire to include an assessment of amotivation. J Sport Exerc Psychol, 2004; 26(2): 191-196

Moreno JA, Cervelló E, Martínez A. Measuring Self-Determination motivation in a physical fitness setting: validation of the Behavioral Regulation in Exercise Questionnaire-2 (BREQ-2) in a Spanish sample. J Sports Med Phys Fit, 2007a; 47(3): 366-378

Moreno JA, Martínez A. Importance of Self-Determination Theory in practice physical sports: Fundamentals and practical implications. Cuadernos Psic Dep, 2006; 6(2): 39-54

Moreno JA, Moreno R, Cervelló E. Physical self-concept as a predictor of the intention to be physically active. Psicy Salud, 2007b; 17(2): 261-267

Mouratidis A, Lens W, Vansteenkiste M. How you provide corrective feedback makes a difference: The motivating role of communicating in an autonomy-supporting way. J Sport Exerc Psychol, 2010; 32(5): 619-637

Moustaka FC, Vlachopoulos SP, Kabitsis C, Theodorakis Y. Effects of an autonomy-supportive exercise instructing style on exercise motivation, psychological well-being, and exercise attendance in middle- 
age women. J Phys Act Health, 2012; 9(1): 138-150

Ntoumanis N. A self-determination approach to the understanding of motivation in physical education. Brit J of Educ Psychol, 2001; 71(2): 225-242

Nunnally JC, Bernstein IH. Psychometric Theory. Nueva York: McGraw-Hill; 1994

Puigarnau S, Camerino O, Castañer M, Prat Q, Anguera MT. The importance of the support to the autonomy in practitioners of sports centers and fitness to increase its motivation and adhesion. Rev Int Cienc Deporte, 2016; 12(43): 48-64

Sánchez J, Núñez J. Preliminary analysis of properties Psychometric of the spanish versión of Basic Psychological Needs Scale in physical exercise. Rev Iber Psic Ejerc Dep, 2007; 2(2): 83-92

Tuero C, Márquez S. Lifestyles and physical activity. In S. Márquez \& N. Garatachea, Physical activity and health. Madrid: Díaz de Santos, 35-50; 2009

Vallerand RJ. Toward a hierarchical model of intrinsic and extrinsic motivation. In M. P. Zanna (Ed.), Advances in experimental social psychology. Nueva York: Academic Press, 271-360; 1997

Vallerand RJ. Intrinsic and extrinsic motivation in sport and physical activity. A review and a look at the future. En G. Tenenbaum y R.C. Eklund (Eds) Handbook of sport psychology. Nueva York: John Wiley, 59-83; 2007

Vallerand RJ. The Psychology of passion. A Dualistic Model. New York: Oxford University Press; 2015

Vlachopoulos SP, Michailidou S. Development and initial validation of a measure of autonomy, competence, and relatedness in exercise: The Basic Psychological Needs in Exercise Scale. Meas Phys Educ Exerc Sci, 2006; 10(3): 179-201

Wold B. Health-Behaviour in schoolchildren: A WHO cross-national Survey. Resource Package Questions 1993-4. Norway: University of Bergen; 1995

\section{Corresponding author:}

\section{Marta Leyton Román}

Associate Professor

University Autónoma of Madrid

C/ Francisco Tomás y Valiente, 3, 28049 Madrid

E-mail: marta.leyton@uam.es 